\title{
Localisation et importance des différents dépôts adipeux selon l'état corporel chez des brebis à queue grasse
}

\author{
N Atti 1, F Bocquier 2, G Khaldi 1, M Thériez 2 \\ 1 INRA, département de Zootechnie, 2080 Ariana, Tunisie; \\ 2 INRA, département Élevage et Nutrition des herbivores, 63122 Saint-Genès-Champanelle, France
}

\begin{abstract}
Summary - Fat tissue distribution and its variation related to body condition in fat-tail ewes. Fat tissue distributions of fat-tail (QG) Barbarine sheep were compared to published thin-tail (QF) data. Total fatty tissue mass (DAT) was always higher in QG than in QF ewes. Most of the allometric coefficients for fatty tissues of QG ewes agreed closely with corresponding QF results. Surprisingly, allometric values for fat-tail deposits were closer to those for internal fat than to those for subcutaneous fat.
\end{abstract}

La rusticité des races ovines à queue grasse (QG) du Moyen-Orient est classiquement attribuée à la présence des dépôts adipeux caudaux, qui n'existent pas chez les races ovines européennes dites à "queue fine" (QF). La répartition des lipides selon l'état d'engraissement a été décrite chez des brebis QF par Russel et al (1971) chez des brebis Blackface et celle des tissus adipeux par Teixeira et al (1989) chez des brebis Rasa Aragonesa. Par contre, de telles descriptions n'existent pas chez les QG. Ce travail a pour objectif de confronter nos mesures sur les brebis Barbarine $(Q G)$ à celles de la littérature (QF).

Matériel et méthodes - Seize brebis adultes et taries de race Barbarine à différents états d'engraissement ont été abattues et disséquées. Les contenus digestifs ont été pesés après abattage, ainsi que le gras mésentérique et omental ( $G M+G O)$. Après réfrigération, la demi-carcasse gauche et la queue entière ont été disséquées (gras, muscle et os). Les tissus adipeux ont été regroupés en sous-cutané (GSC), intermusculaire (GIM), rénal et pelvique (GRP). Le tissu adipeux caudal (GC) a été individualisé. Pour chacun de ces tissus adipeux, nous avons calculé sa relation d'allométrie avec d'une part le poids vif vide (PVV, $\mathrm{kg}$ ) et d'autre part avec les dépôts adipeux totaux (DAT, $\mathrm{kg}$ ) : $\log _{10}($ tissu $)=a \cdot \log _{10}(P V V)+b$. Afin de comparer nos résultats à ceux obtenus chez une autre race de brebis rustique à queue fine (QF : Rasa Aragonesa), nous avons établi les mêmes relations sur nos données et les leurs (Teixeira et al, 1989). Ensuite, nous avons calculé, pour les 2 types de brebis, les quantités de différents tissus adipeux à même PVV ou à même DAT, et comparé les valeurs des coefficients d'allométrie.

Résultats et discussion - Parmi les brebis Barbarine de l'échantillon, celles qui avaient les dépôts adipeux caudaux extrêmes 1,06 et $3,38 \mathrm{~kg}(\mathrm{~d}=2,32 \mathrm{~kg})$ avaient respectivement des dépôts adipeux totaux de 4,83 et $14,59 \mathrm{~kg}$. La variation de masse adipeuse caudale, dans cette situation extrême, représentait donc $24 \%$ des variations totales du tissu adipeux. Cette proportion n'est pas très éloignée des résultats moyens rapportés dans le tableau I.

Les 2 races ovines Barbarine (QG) et Rasa Aragonesa (QF) sont de format assez voisin, avec des amplitudes de variation du PVV similaires (de 25 à $50 \mathrm{~kg}$ ). En utilisant les relations d'allométrie, on a calculé que les brebis QG ont des proportions de dépôts adipeux totaux (DAT \% PVV) systématiquement plus importantes que les QF, quel que soit le PVV. Pour un PVV de $50 \mathrm{~kg}$, DAT $(\mathrm{QG})=39,8 \%$ vs DAT $(\mathrm{QF})=32,8 \%$ pour un PVV de $25 \mathrm{~kg}$, DAT $(\mathrm{QG})=14,8 \%$ vs $\mathrm{DAT}(\mathrm{QF})=6,5 \%$. Cet écart est en partie dû à la présence de la queue chez les brebis lourdes qui ont des masses adipeuses (hors gras caudal) très proches (DAT-GC $(\mathrm{QG})=$ $31,6 \%$ vs DAT $(\mathrm{QF})=32,8 \%$. En revanche, chez les brebis légères, les brebis à $Q G$ ont 2 fois plus de TA que les QF (DAT-GC (QG) $=11,4 \%$ vs $\mathrm{DAT}(\mathrm{QF})=6,5 \%$. Si on examine la répartition des différents tissus adi- 
peux chez des brebis grasses, comportant $17 \mathrm{~kg}$ de dépôts adipeux totaux, on observe que les brebis QG ont moins de dépôts internes $(7,3 \mathrm{~kg})$ que les brebis QF $(11,2 \mathrm{~kg})$. Elles ont par contre plus de gras externe (sous-cutané : 6,5 vs $5,7 \mathrm{~kg}$ ) auquel s'ajoute le gras caudal $(3,2 \mathrm{~kg})$.

Les coefficients d'allométrie entre les différents tissus adipeux et le PVV ou les DAT (tableau I) sont en accord avec les descriptions de Hammond (1932). Dans les 2 races, le tissu sous-cutané présente les plus fortes allométries (SC/PVV(QG) = 3,28 vs $\mathrm{SC} / \mathrm{PVV}(\mathrm{QF})=4,70$ ), alors que les dépôts intermusculaires ont les valeurs les plus faibles (respectivement 1,46 et 2,42 ). Pour les autres tissus, il semble que l'ordre de dépôt soit différent entre les 2 races : chez la Barbarine, les dépôts de gras omental et mésentérique (GO + GM) précèdent les dépôts périrénaux et pelviques (GRP), alors que c'est l'inverse chez les Rasa Aragonesa. Paradoxalement, le gras caudal a des coefficients d'allométrie moyens (GC/PVV $=2,19$ et GC/DAT = $0,85)$, voisins de celui des dépôts internes et très inférieurs à celui du gras souscutané.
Sachant que les teneurs minimales en lipides corporels se situent vers 2 à $3 \%$, on peut considérer que les brebis Rasa Aragonesa sont proches de ce seuil, avec $6,5 \%$ de DAT lorsqu'elles pèsent $25 \mathrm{~kg}$ de PVV, alors que les brebis Barbarines, par extrapolation et en supposant que le coefficient d'allométrie est constant, atteindraient ce seuil à $14 \mathrm{~kg}$ de PVV. D'après les données dont nous disposons, le tissu adipeux caudal de la brebis Barbarine semble donc constituer un organe de réserve plutôt par sa masse que par sa plasticité relative. En effet, il représente encore $23 \%$ des dépôts adipeux totaux chez les brebis émaciées.

Remerciements - Ce travail a été réalisé, grâce à un financement du ministère des Affaires étrangères, dans le cadre du projet d'amélioration des techniques d'élevage ovin en Tunisie.

Hammond J (1932) Growth and development of mutton qualities in the sheep, 2nd ed Oliver \& Boyd, Edinburgh

Russel AJF, Doney JM, Gunn RG (1971) Anim Prod 13, 503-509

Teixeira A, Delfa R, Colomer-Rocher F (1989) Anim Prod 49, 275-280

Tableau I. Poids $(\mathrm{kg})$ des tissus adipeux chez la brebis Barbarine (a) et coefficients d'allométrie entre les différents tissus adipeux et le poids vif vide (PVV) ou les dépôts adipeux totaux (DAT) chez les brebis Barbarine et Rasa Aragonesa (b) *.

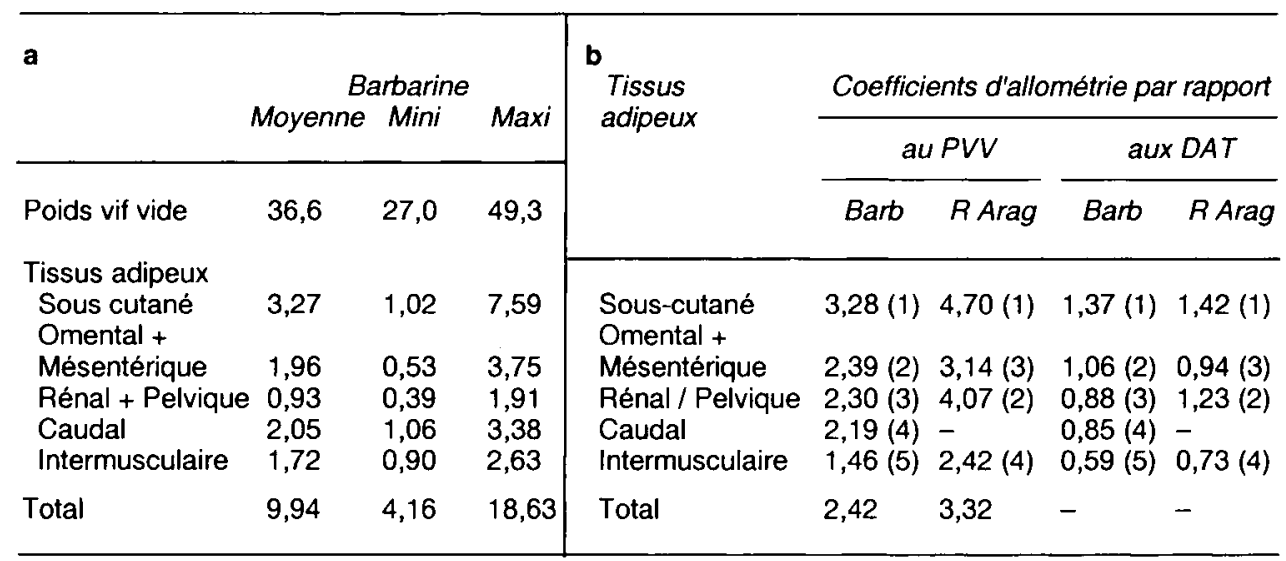

* D'après Teixeira et al (1989).

(i) Ordre d'allométrie décroissant. 